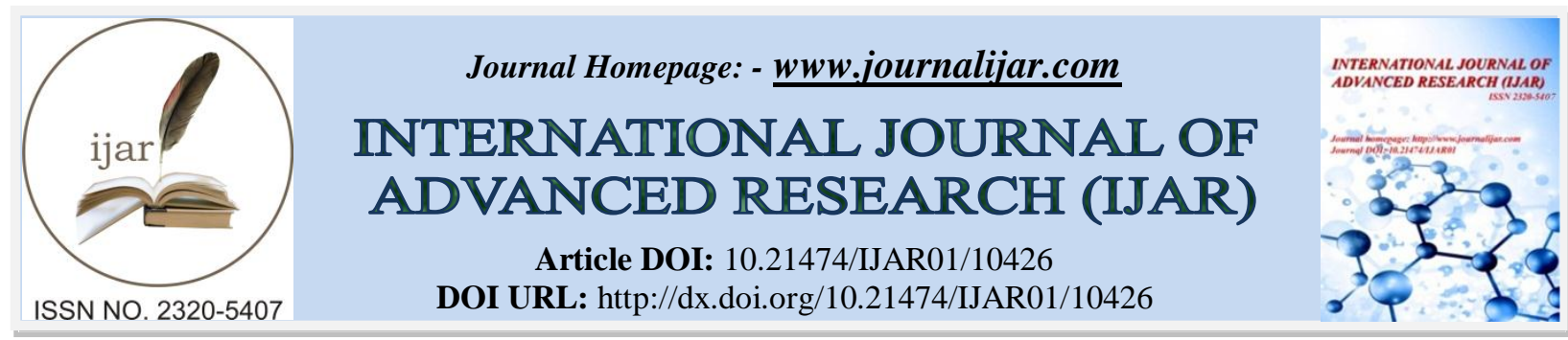

RESEARCH ARTICLE

\title{
GENDER EQALITY AND SOCIO- ECONOMIC EMPOWERMENT OF WOMEN IN INDIA : GENDER STEREOTYPE IN INDIA
}

\section{Pallavi Pal}

Phd. Research Scholar, Department of Law, University School of Law and Legal Studies, Ggsipu, Postal Address: 65a, Lig flats, Prasad Nagar, New Delhi-110005.

\section{Manuscript Info}

.a.......................

Manuscript History

Received: 30 November 2019

Final Accepted: 31 December 2019

Published: January 2020

\section{Abstract}

This paper comprises of different agendas prepared for gender equality and socio economic empowerment of women in today's world. Gender equality is not just a women's issue, now it has acquired a wide recognition and it is a development issue. Women economic empowerment is essential for economic development, growth and poverty reduction not only because the income it generates but also to break the vicious circle of life. We can achieve gender equality by educating girls; increasing literacy rates among women; increasing early childhood development interventions; increasing women's labour force participation and strengthening labour policies affecting women; improving women's access to credit, land and other resources; promoting women's political rights and participation; expanding reproductive health programs and family support policies. Empowering women and girls is not only the right thing to do, it's also smart economics and vital to ending poverty and boosting shared prosperity. The meaning of gender stereotype is simply the generalisations about the roles of each gender. These are generally neither positive nor negative. Since each person has individual desires, thoughts and feelings, regardless of their gender, these stereotypes are generally incredibly simplistic and do not describe attributes of every person of each gender. There is a general notion that a female stereotypic role is to marry and have children, she puts her family and children welfare before her own, a women are often nurse and not doctors, be loving, compassionate, caring, nurturing, and find time to feel sexy and beautiful. The feminist movement, or women's liberation movement which is a major initiative towards empowerment of socio-political force in early sixties, has lobbied for the rights of women and minorities. Feminists have fought hard to challenge and redefine traditional stereotypic gender roles.

Copy Right, IJAR, 2020,. All rights reserved.

\section{Introduction:-}

Man and woman are two halves of humanity; neither can reach its highest creative excellence without the cooperation of the other. Through the ages we have placed woman on a pedestal 'mother of mankind'. Paradoxically, she has been facing the most horrendous cruelties on her, without any reason and without just cause. 
Though we have entered the new millennium but the status of women is still same as it used to be in earlier times. This problem is mainly due to traditional bias and prejudice towards this section of society.

Women's issues have been a matter of grave concern for a long time but have attracted pointed attention only in the past few decades. Over the years, the laws pertaining to women have undergone various changes, which not only recognise their rights but also afford protection against exploitation. In spite of all these laws, due to lack of understanding about the realities being faced by women- at home, at place of work or in court; often lead to inequality and injustice to women. This suffering is traced to the deep rooted social values in an essentially male dominated society. Education and media exposure has contributed a lot in making indian women aware of few of her rights and her position in the society. The preamble to our constitution refers to the promise of social justice. Right to equality has been enshrined as a fundamental right under chapter iii of the constitution, which also provide a provision for affirmative action in favour of women. Despite these constitutional provisions, special laws have been enacted to promote gender justice; the status of women continues to be cause of concern not only in our country but also in most countries of the world.

Gender inequities throughout the world are among the most pervasive, though deceptively subtle forms of inequality. Gender equality concerns each and every member of the society and forms the very basis of a just society. Today as we stand at the beginning of the 21 st century, we are still unable to boast of a society where there is total gender equality or gender equity.

It is hard to believe that the discrimination against individuals on the basis of their sex, race, age, sexual orientation or health status still exists in most countries. We may not want to accept the fact that the sexual violence is common in all culture and women are still victims of rape, battering and sexual harassment each day, despite legislation prohibiting such violence, common policing, workplace policies, counselling and training programs exist. Yet this is the reality for most women.

The fact that points towards the sex stereotype is that the individuals think of 'man' when they hear a word 'surgeon' this illustrates how we hold beliefs, attitudes, the stereotype that influence our perception of the world around us. Likely, which sex do you associate with elementary school teacher? With model? With engineer? Most individuals still indicates that elementary school teachers are female, models are female, and engineers are male. Individuals also mark the occupation if they believe the sex of the person performing this job is typical. Stereotypes refer to individuals cognitions that typically do not correspond to reality. A stereotype is a picture in the head not an accurate mirror of the real world. It generally refers to pre conceived notions which force an individual to think on the usual tangent regarding jobs according to the sex of the individuals.

Stereotypes occur when individuals are classifieds by others as having something in common because they are members of a particular group or category of people. Gender stereotypes are a psychological process which illustrates structured sets of beliefs about the personal attributes of men and women. The gender stereotypes generally begin from the early childhood, as the awareness of the contents of gender role stereotypes begins in the preschool years and is rather well-developed by the time children enter first grade. Parents are among the more important socializing agents for children in shaping values, beliefs and behaviours related to gender. Furthermore knowing the sex of the baby conjures up all kinds of personality characteristics and physical attributes even when these factors are not present in the child. Parents communicate their stereotypes to children in numerous ways. Boys are given building blocks, sports equipment and model vehicles. Girls, on the other hand, are encouraged to play with dolls, dolls houses and miniature household appliances.

\section{As we move further we see that the images of women have not been static and have undergone various changes:}

The cultural ideas, values, norms and beliefs play a significant role in creation of women images and the differentiation of gender roles. The purpose of the present paper is to understand the images of femininity in indian society from ancient to modern times. India, being a heterogenous society, presents conflicting women images. The image of indian womanhood has been displayed by the normative model and has proved a remarkable consistency. There are various cultural images of women. She is called as 'pativrata' - unconditional devotion to husband, 'glorified motherhood' as bharat mata image. 
Firstly on the societal plane, the perception of different categories of women is distinctly shaped/ conditioned by the popularly accepted female stereotypes. Secondly, at the interpersonal level the situation is slightly different as these images frequently impinge in a variety of ways. The indian girls often have to face the hardships of life because they grow up with deep rooted sense of fear and insecurity which not only restricts their social mobility in the mundane day-to-day life and this also psychologically cripples them. These gender dichotomies, flowing almost directly from the popular images fostered most significantly these images in most indian families. Thirdly, these images leave a deep imprint upon women's self-perception.

Advertising has become a tool for stereotypes for women:

Domesticity is the second role of two dimensional image of femininity in advertising. Advertising has been a target of attack and scrutiny. This can be explained by a critical focus on sex role portrayal which is advertised in close relationship, which exists between advertising, the consumer goods industry and the crucial economic role of women as consumers. Generally it is shown in advertisement a woman's goal in life is to attract opposite sex and attain a man. Women are shown in advertising as always young and attractive. They are frequently depicted as sexual objects. Women in advertisements are restricted to home and isolated from other women outside home, man is her favourite companion.

\section{Sex stereotyping in the media:}

There are sex stereotypes that are found in different media and they are far more dangerous than the overtly obscene advertisements. In india the sex stereotyping is witnessed by the woman behaving like mythological sita and savitri which are reflections of sacrifice and are docile, submissive, sentimental, and superstitious also they are incapable of rational action. Their primary duty is being wives, companion and devoted mothers. This image of women has been disseminated by the films. They have a package formula for women: where the women are shown as traditional, truly indian women, who are devoted, son producing wives etc. Even so far the protests and criticisms against women have not had much effect on the commercial hindi film industry. Television also perpetuates sex stereotypes. These women sita and savitri who have given way gracefully to an alien creature who is a new role model for the indian women who has the best of both worlds. They are economically independent, progressive, ambitious and very feminine. But what is being peddled here is the advanced western lifestyle which is far removed from the average indian woman's struggle to survive totally neglecting and never questioning her reality. Even though sixty percent women are engaged in agriculture, still the radio programmes for rural areas are only directed to men. Those programmes which have women involvement, never discuss technology, banking facilities, new laws or any such issues.

For the emancipation for the women in every field, economic independence is of paramount importance. Along with economic independence, equal emphasis must also to be laid on the total development of women. This can be done by creating awareness among them about their rights and responsibilities, the recognition of their vital role and work they do at home. If necessary, a social system must evolve. The society must respond and change its attitude.

Stereotyping was accepted by respondents as an essential tool of advertising. It was understood that without easily recognised stereotypes it would be hard to tell a story, or communicate a message, in the short span of time using advertisements. Respondents generally do not wish to see regulation which was so strict that the advertisers. Stereotype advertising is one of the successful strategies to the changing consumerism and cultural norm there are enormous opportunities to empower women and as well to the marketers to promote their brands in a socio-ethically positive and sensitive way. One of the recent happening in indian advertising industry and a subject of discussion in a number of social media catch the eyeballs of many viewers from nationally and globally by breaking the social norms for promoting the brand "tanishq" (from titan the tata group), a leading jewellery designer and retailer from india. Tanishq has launched a campaign for its latest wedding collection of jewelleries in october 2013 during festive and wedding season. It took an advertising campaign to talk about women's remarriage, a subject which fast changing modern indian society is yet to embrace completely. The brand targets young women who are looking for different designs. Tanishq jewellery is a trend setter that pushes fashion boundaries in the premium jewellery market in india. The marketer boldly took a business risk by pushing the boundaries of social norms and stereotypes that plagued south asian culture in their latest ad. In a culture where fair skin is favoured and rewarded and widows and single mothers are shunned, tanishq has embraced both and depicted them beautifully, dark skin, second marriage and all. 
This ad has been hit, making all the headlines. Tanishq has very positively highlighted the social issues with an effective brand promotion with the stereotypes. Widow remarriage is still a taboo in india, particularly rural and tribal parts the country among certain communities. It was not only the first time in india that the various consumer brands are pro.

\section{Education is a key to empowerment of women and eradication of stereotypes:-}

Laws are not enough to combat the evil. A wider social movement of educating women of their rights, to conquer the menace, is what is needed more particularly in rural areas where women are still largely uneducated and less aware of their rights and fall an easy prey to their exploitation.

Most studies show that how the education of a girl child has positive impact on infant mortality, maternal mortality, health and hygiene, productivity. Education is a key to empowerment, which in turn is a key to achieving other development goals. Though the enrolment of girl children has been growing at an impressive rate in recent years, yet it is said that there exists a gap of about twenty percentage points between the enrolment of girls and boys, be it in primary, secondary or higher education level.

However, the life of ordinary women has been confined to the four walls of her household, overburdened with domestic works, controlled of her mobility and personal freedoms by the men of the household since time immemorial. The real story of women is not recorded in any of the past literature. Still it is worthwhile to mention about the great indian women of the past as a background story for the continuing struggle for autonomy, equality and empowerment.

\section{Stereotype v/s prejudice:-}

Often the terms stereotypes and prejudice are confused. Stereotypes, on one hand, are standardised and simplified conceptions of groups based on some prior knowledge. On the other hand, prejudices are preconceived judgements formed without grounds or sufficient knowledge. Stereotypes are created on some familiarity of a person whereas prejudices are claims made without knowledge or familiarity of a person.

When prejudice occurs, stereotyping and description may also result. In many cases, prejudices are based upon stereotypes. A stereotype is a simplified assumption about a group based on prior assumptions. Stereotypes can be both positive and negative. These can lead to faulty beliefs, but they can also result in both prejudice and discrimination. Prejudices must be reduced as much as possible in social relationships so that people in the societies have mutual respect of one another and no one is considered "less" than the others.

\section{Conclusion and Discussion:-}

Concluding the paper by saying that the fight for justice by females or cry for gender equality should not be treated as a fight against men. It is a fight against traditions that have chained them, it is a fight against attitude that is ingrained in the society, and it is a fight against lakshman rekha which is different for men and different for women. When women are fully involved, the benefits can be seen immediately: families are healthier and better fed; their incomes, savings and reinvestment go up. And what is true of families is true of communities and in the long run of whole countries. We must make sure that women and girls have all the skills, services and self-confidence they need to protect themselves. In other words, they must be empowered. Stereotypes are simplifications of social origin and social development being transmitted from generation to generation. Some may be universal, but in general, stereotypes are known, used and transmitted inside a certain group or a certain culture. Stereotypes also perform the justifying role: they justify our behaviour and the social system or the behaviour of a social group with which we identify ourselves. Stereotypes are not essentially negative. They actually help us in understanding complicated processes ruling the social world, reduce uncertainty and provide a sense of security. 